\title{
Establishment Network by Using FSO Link Based on MD Code for Hybrid SCM-SAC-OCDMA Wireless System
}

\author{
Rashid Ali Fayadh ${ }^{1}$, Mousa K. Wali ${ }^{2}$, Mehdi F. Bonneya ${ }^{3}$ \\ ${ }^{1}$ Departement of Electrical Power Engineering, College of Electrical Engineering Techniques, \\ Middle Technical University, Iraq \\ ${ }^{2}$ Departement of Medical Instrumintation Engineering, College of Electrical Engineering Techniques, \\ Middle Technical University, Iraq \\ ${ }^{3}$ Departement of Electrical and Electronic, Kut Technical Institute, Middle Technical University, Iraq
}

\section{Article Info}

Article history:

Received Aug 19, 2017

Revised Jul 16, 2018

Accepted Jul 30, 2018

\section{Keyword:}

Free Space Optics

Multi-Diagonal, OCDMA

Radio Over Fiber

SCM-SAC-OCDMA

UWB Technology

\begin{abstract}
Since the wireless systems are working under nature environments and influenced by turbulence, weather in Iraq that leads to extended amount of fading signal, dissipation or attenuation. Basic "hybrid Subcarrier Multiplying Spectral Amplitude Coding (SCM-SAC) of Optical Code Division Multiple Access (OCDMA)" indoor or outdoor optical system depends on generally "Multi-Diagonal (MD)" security code by using optical space known as "Free Space Optic (FSO)" that was proposed in this work. It is found that the mention hybrid wireless systems can be used in operating mesh networks. The main proposed idea of hybrid optical technique was analyzed and simulated by normally taking into simulation account that the directly effecting by rain and haze attenuations. In addition, there are mention and description for atmospheric effects, FSO mesh network, modulation scheme, simulation, and the data security. From simulation results, the hybrid system using MD code produces reduced "bit-error rate (BER)" at heavy storm rain to distance or range of $500 \mathrm{~m}$ and at drizzle rain up to $2500 \mathrm{~m}$ range. And also investigates the performance of using the proposed system with radio over fiber (RoF) for UWB signals through indoor propagation in building applications of wireless channel.
\end{abstract}

Copyright $@ 2018$ Institute of Advanced Engineering and Science. All rights reserved.

\section{Corresponding Author:}

Rashid Ali Fayadh,

Departement of Electrical Power Engineering,

Middle Technical University,

Al-Dora Road, College of Electrical Engineering Techniques, Baghdad, Iraq.

Email: rashidfayadh47@gmail.com

\section{INTRODUCTION}

Recently, the FSO is becoming wide used and nowadays very important for communication. This FSO is a technology of laser-driven that is supporting wide bandwidth range. This technology is easy to install for optical connections for the free license, last-mile, campus environments, and high security. In addition, the FSO is an important solution of the required cost-effective, growing popularity of low cost or inexpensive connection clients, secure wireless networks in outdoor, and much enhanced by the Radio Frequency (RF) technique. Technical hybrid Radio over fiber (RoF) of SAC-OCDMA was proposed to carry over long distance the high data capacity of digital information over link of fiber protected and maximize or optimize the data amount and increase the number of transmission users as in [1].

The "hybrid subcarrier multiplying SCM-SAC-OCDMA" optical system that based on multidiagonal security data code by using link of fiber is investigated for reducing the "multi-access interference (MAI)" with wireless high propagated data bit rate and that leads to increase the number of defined area for active or connected users as represented and improved bywork of [2] that is focusing in this field. TheFSO 
optical systems are starting to be nowadays accepted in the private or military marketplace as a normal solution to replace an expensive fiber optic to be based solutions. To reduce the cost-effective between the fiber optic infrastructure and end users, the communication technology of FSO was produced by [3]. Moreover, FSO links are a modern emerging optical technology which has been found their applications in long-haul and short links for communications same as "Wireless Local Area Network (WLAN)", and "Local Area Network (LAN)". In addition, the disadvantage of FSO is suffering from unexpected and sudden changing in weather situations [4].

In this paper, mesh network was proposed by illustrating original "hybrid SCM-SAC-OCDMA" optical system that based on multi-diagonal security code with the FSO link to provide access real-time of processing communication between WLAN controllers and lightweight access operating points to deliver RoF management, centralized security policies, secure of system, and quality of service (QoS) [5]. Also this mesh network was designed to reduce the space attenuations of rain and haze in the optical system performance depending on the tropical conditions in weather of Iraq sector [6]. In 2002, "the US Fedral Communications Commission (FCC)" licensed the spectral frequency band from $3.1 \mathrm{GHz}$ up to $10.5 \mathrm{GHz}$ with "transmitted power less than $-41.3 \mathrm{dBm} / \mathrm{MHz}$ " for indoor and outdoor wireless propagation with two major techniques impulse radio and frequency division multiplexing UWB systems.

This propagation is limited for several meters (less than 30 meters) and increasing the coverage area is required for future applications. In addition, to improve the availability of undisrupted wireless service over different networks, ultra wideband over fiber technology was chosen to show the performance of the proposed system in terms of reducing the probability bit error. As the wireless networks of low power consumption are required in future wireless technology and since the RoF technique is widely used over the world, ultra wideband-over fiber (UWBoF) system was integrating to multiplex the received optical signals. This technique is more suitable for wireless network systems to get the requirements of low power consumption, low cost, high data rate, low complexity, and more users during wireless connectivity [7].

The remainder of this work is organized and represented as follows. Section 2 shows the FSO mesh network. Section 3 displays the system design. Section 4 devotes for specific space attenuations or distortion of nature haze and rain. Section 5 presents the discussion and results of "hybrid SCM-SAC-OCDMA" system by using MD security code version based on the FSO. Section 6 indicates the application of the proposed system. Conclusions are given in Section 7.

\section{FSO MESH NETWORK}

An optical technique of using the modern mesh wireless networks was begun in neighborhoods of several states in the world establishing their free operating private networks depend on low-cost, flexibility in expansion, self-administration, and high data rate. The mesh network of high redundancy degree is composed for serially several of interconnected mesh nodes [8]. The wavelength of FSO mesh network should be chosen to have minimum absorption and the atmospheric transmission window is designed to be suitable due to space attenuation. In the FSO, the wireless network is used such a propagation bridge over coverage area. In FSO mesh network, each node in the system is contact or connected to any of other used nodes, either directly or indirectly by series of connection hops.

Better performance for system with more number of propagation nodes [9]. Furthermore, the FSO mesh network offers easy node with higher reliability and it is not affecting on the network that is getting interrupt in any previous node, and restricting the reception or transmission ranges by natural limitation at changing weather conditions environments as shown in Figure 1. The weather conditions in this channel are classified into three categories such as rain, clouds, and clear weather. Conditions in clear weather are characterized by low attenuation and long visibility while cloudy weather are characterized by low attenuation, short visibility, and high humidity. In this work we concentrate on haze particles and rain droplets which are characterized by the presence of rain or haze and they can produce severe effects depending on rainfall rate. Because of these conditions, there is free space loss $\left(L_{s}\right)$ defines the signal strength depending on wavelength $(\lambda)$ and visibility range $(\mathrm{V})$ is given by [10]

$$
L_{s}=\left(\frac{\lambda}{4 \pi V}\right)
$$




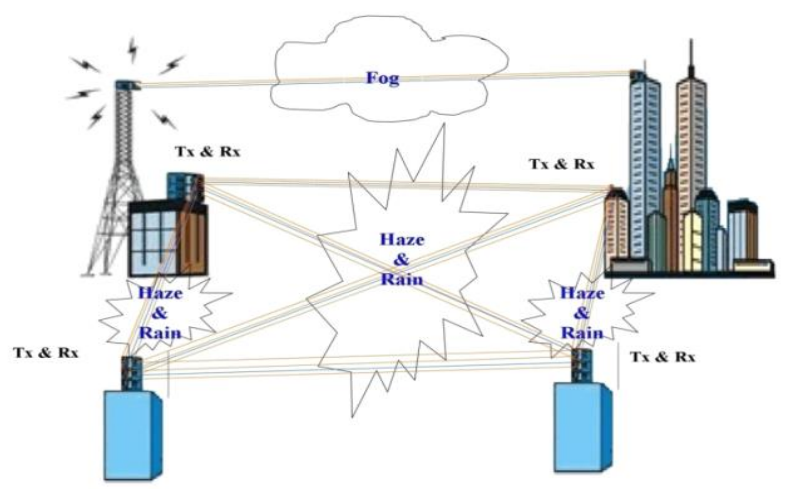

Figure 1. The proposed implementation of FSO network

\section{SYSTEM DESIGN}

In this work, the proposed system of SCM-SAC-OCDMA wireless network was designed and using MD code that is shown in Figure 2. In transmitter side, the external optical modulator (EOM) is used to combine data rate with signals of independent unipolar of communication digital signal and to the code sequence they are optically modulated[11].An EOM such as modulator filter of "Mach-Zehnder" is connected to merge the code sequences with the RF signals together and transmits over FSO link [9]. While in the other side of wireless receiver, the optical splitter design is utilized for separating code sequences of different modulation. "Fiber Bragg Grating (FBG) optical filters" can be used to filter the MD code sequences and transferring these sequences to the photo-detector (PD) as a sensor at the other side of receiver [12]. Therefore, signals of the SCM are combined or mixed with each sequence of MD code and they are splitting by using equipment of electrical splitter with "band pass filter (BPF)" to filter the rejected or unwanted signals.

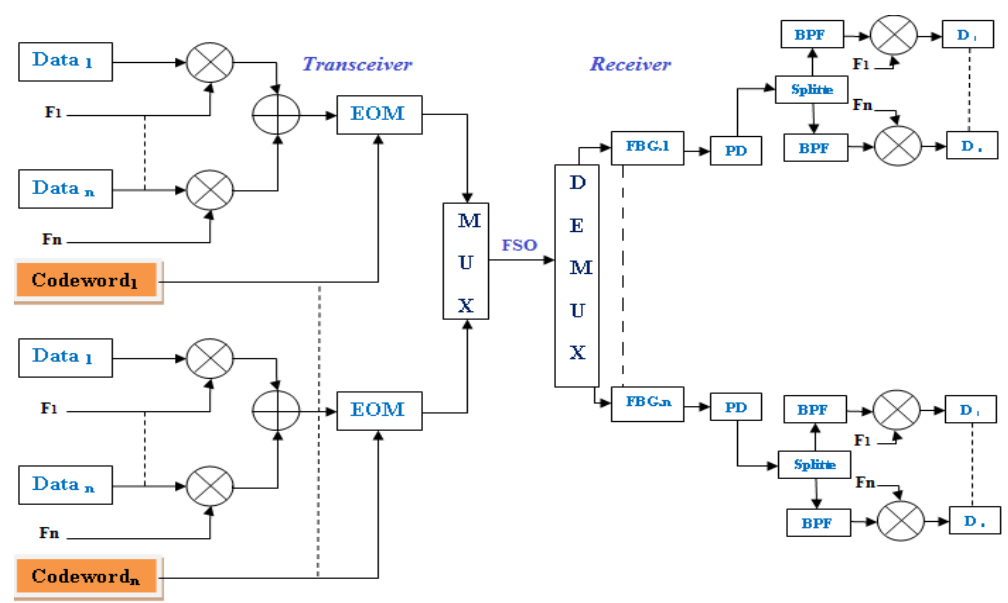

Figure 2. The "SCM-SAC-OCDMA" performance diagram that based on FSO

\section{SPECIFIC SPACE ATTENUATION OF HAZE AND RAIN}

The space or optical beam attenuation is defined as induced geometric losses due to the spreading of optical beam and reduced the power level of signal as it travelled from transmitted end to receiverend. The hybrid signals are travelled by light in the free atmosphere. However, tropical in the region such as Iraq, the haze or rain becomes dominant factors of the signal attenuation which is caused by signal deterioration. In addition, expected or unexpected conditions for nature parameters such as haze and rain have a direct effect on the carrying light [13]. Consequently, the specific space attenuations of haze and rain are expressed as listed below: 


\subsection{The Specific Rain Attenuation} given by

The rain attenuation for FSO links can be reasonably well approximated byempirical formula and is

$$
\alpha_{\text {spec }}=\beta R^{q}
$$

where $\alpha_{\text {spec }}$ is defined as the rain attenuation in $\mathrm{dB} / \mathrm{km}, \mathrm{R}$ is defined as the fall rain rate in $\mathrm{mm} / \mathrm{hr}$, and $\beta$, $\mathrm{q}$ are coefficients that independent on temperature and frequency.

\subsection{The Specific Haze Attenuation}

The part of this paperis focused on the analysis of haze attenuation at different visibility ranges.

$$
\alpha_{\text {spec }}=\frac{10}{\log _{10}(\alpha(\lambda))}(\mathrm{dB} / \mathrm{Km})
$$

As the wavelength $(\lambda)$ plays a major rule in haze attenuation of optical signal, $\lambda$ have to be known in nanometers, an attenuation coefficient of the affected space is approximated by [12].

$$
\alpha(\lambda)=\frac{3.912}{V(\lambda / 550)^{-q}}
$$

where $\alpha_{\text {spec }}$ is the haze attenuation in $\mathrm{dB} / \mathrm{km}, \mathrm{V}$ defines the visibility range in $\mathrm{km}, \lambda$ is wavelength in $\mathrm{nm}, \mathrm{q}$ is a coefficient depends on the size of distribution for scattering particles and can be exploited by two models reported by Kruse and Kim [12] and [13]. In addition, it is implemented or supported in the simulation analysis of this work. The $\mathrm{q}$ factor in kruse's model is defined as:

$$
q=\left\{\begin{array}{ll}
1.6 & \text { if }>50 \mathrm{Km} \\
1.3 & \text { if } 6 \mathrm{Km}<V<50 \mathrm{Km} \\
0.1 V+0.43 & \text { if } 1 \mathrm{Km}<V<6 \mathrm{Km} \\
V-0.5 & 0.5 \mathrm{Km}<V<1 \mathrm{Km} \\
0 & \text { if }<<0.5 \mathrm{Km}
\end{array}\right\}
$$

while the $\mathrm{q}$ factor in kim model is defined as:

$$
q=\left\{\begin{array}{l}
\text { if }>50 \mathrm{Km} \\
1.6 \quad \text { if }>50 \mathrm{Km} \\
1.3 \quad \text { if } 6 \mathrm{Km}<V<50 \mathrm{Km} \\
0.585 V^{1 / 3} V<V<6 \mathrm{Km}
\end{array}\right\}
$$

\section{THE DISCUSSION AND RESULTS OF "HYBRID SCM-SAC-OCDMA" SYSTEM BY USING "MD CODE BASED ON FSO":}

The implementation of "hybrid SCM-SAC-OCDMA" optical design that independent on security MD security code with FSO wireless link to any wireless node in proposed mesh network has got simulation by using opti-system software version 9. In above system and during simulation, 2 users within 4 subcarriers were used at reception encoder system with utilizing technical FSO for transmitting as represented in Figure 3. Table 1 illustrates the used scientific parameters for "hybrid SCM-SAC-OCDMA" in the simulation design that based on the MD code and optical FSO with two code weights (W). Using MD code is independent and based on a previous represented study, whichis reported the using MD code which leads to get better performance for wireless system. This performance is comparing with that of using conventional code and employed in the original SAC-OCDMA optical system [14] and [15]. 


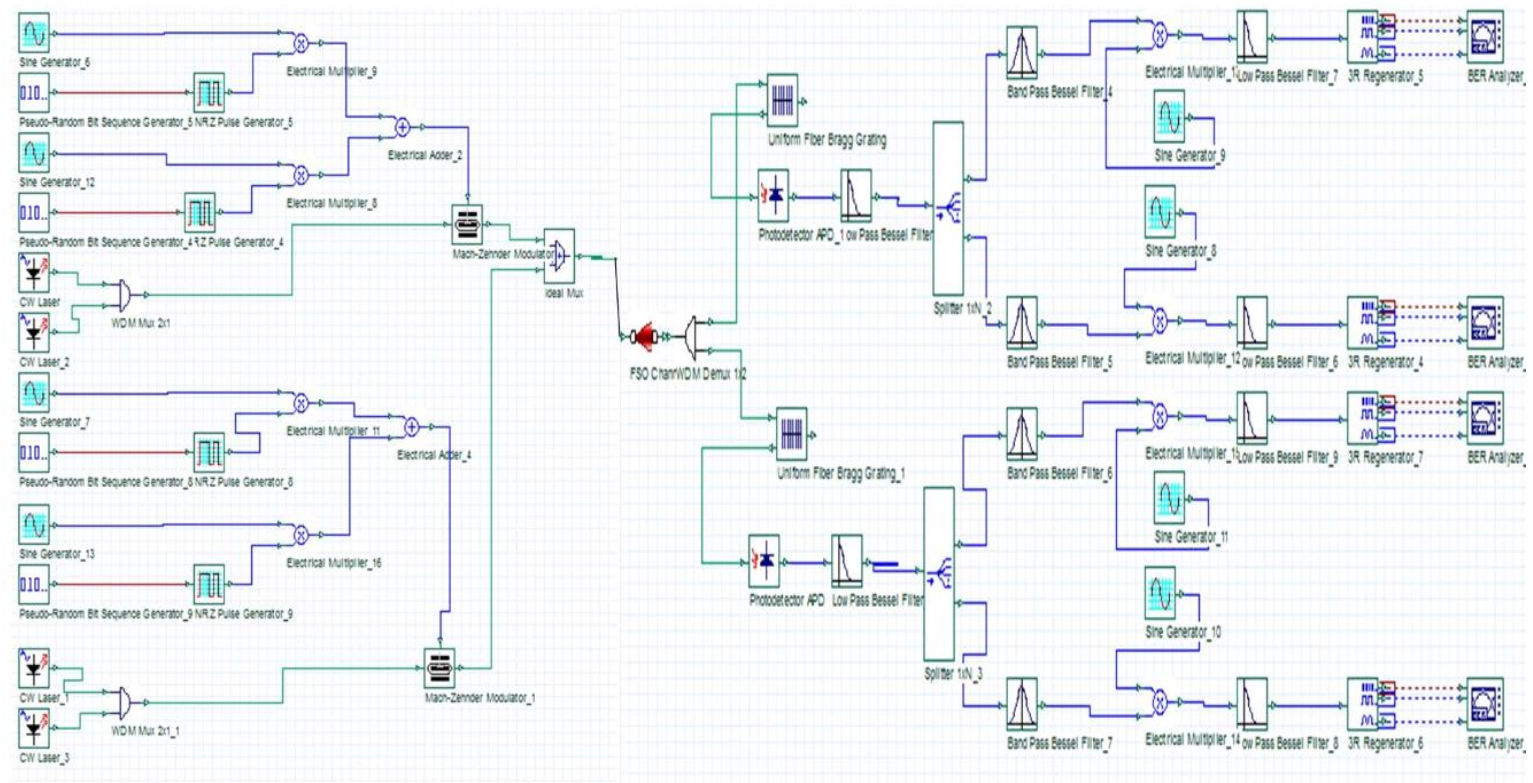

Figure 3. The proposed system analysis for hybrid SCM-SAC-OCDMA

Table 1. Values of the Proposed Design Parameters

\begin{tabular}{lc}
\hline \multicolumn{1}{c}{ Variable } & Value \\
\hline C-Band wavelength & $1550 \mathrm{~nm}$ \\
Propagation power & $6 \mathrm{dBm}$ \\
Number of users & 5 \\
Number of subcarrier & 10 \\
Frequency band & $610 \mathrm{MHz}$ \\
FSO Length & $0.5 \& 2.5 \mathrm{Km}$ \\
Aperture diameter for transmitter & $10 \mathrm{~cm}$ \\
Aperture diameter for receiver & $32 \mathrm{~cm}$ \\
Beam divergence & $2 \mathrm{~m} \mathrm{rad}$ \\
\hline
\end{tabular}

The data in table I are simulated using Optisystem version 7 and Figure 4 represents scientific relationship between BER and data rate for attenuations caused by haze and rain. From the figure characteristic, the data rate is increased to $622 \mathrm{Mb} / \mathrm{s}$ for the hybrid system, where the BER will be $10^{-10}$ at the storm or fast rain. In addition, the BER or probability error isdecreasing when the capacity of data rate is reduced to be fewer than $622 \mathrm{Mbps}$. In addition, figure 4 shows the BER is increased to be $10^{-11}$ when the data rate equals to $622 \mathrm{Mbps}$ under the effect of the natural heavy haze. Therefore, the propagated high data rate is affecting on the operation of hybrid optical system performance.

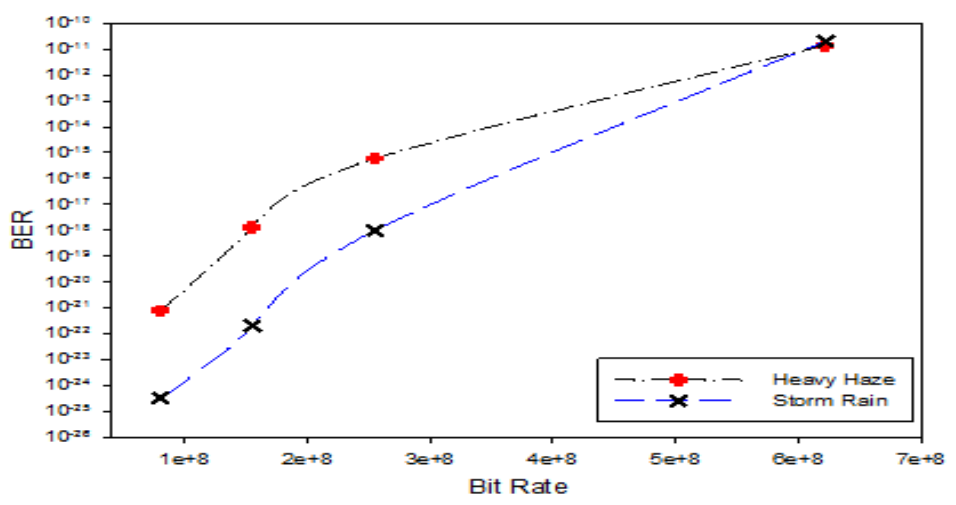

Figure 4. The BER versus data rate 
Attenuations of haze and rain are shown in figure 5 to illustrate the comparison of BER values for different ranges up to $2.5 \mathrm{~km}$. It is cleared that the visibility of light impacts on attenuations and distances of haze at heavy, clear, and light and of rain at strong, storm, drizzle, and light. It is observed that the proposed hybrid system utilizing MD code with FSO optical technique could perform sufficiently very well with the BER of $10^{-12}$ up to $500 \mathrm{~m}$ at the natural storm rain while at the drizzle rain; the BER is $10^{-31}$. At normally heavy or clear haze, the BER is arrived to be $10^{-9}$ and $10^{-15}$ with distance of $2500 \mathrm{~m}$ respectively. So that the system performance is affected by distance that leads to decrease BER at short distances and increase BER at long distances because of attenuation and dispersion of fiber length. This study shows $2.5 \mathrm{Km}$ or more is the worst situation for rain and haze attenuations.

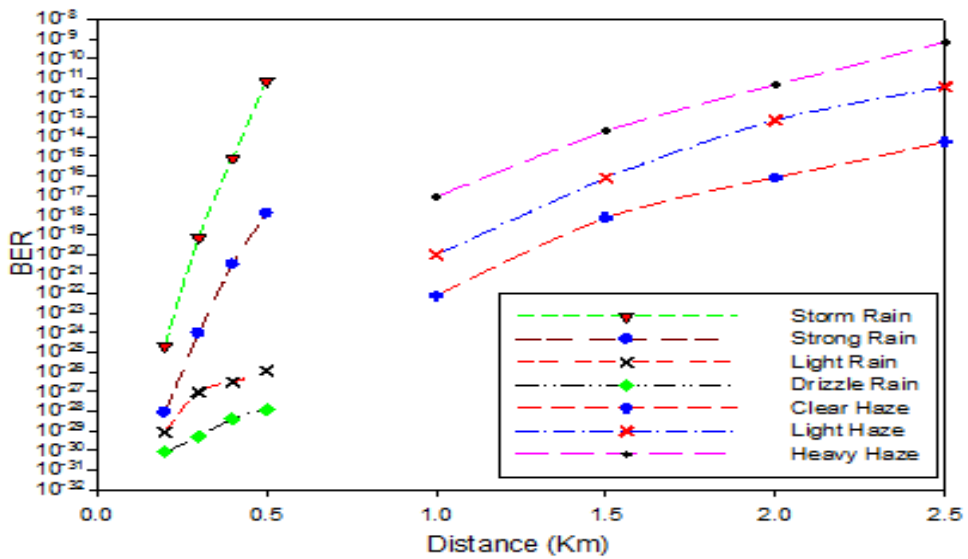

Figure 5. BER against the distance

Figure 6 illustrates the transmitted power against BER and compared with storm rain and heavy haze. In general, it is absorbed that the power transmission has impact on the hybrid system and the BER decreases through increasing the power. Figure 4 also shows the range of power transfer from 6 to $9 \mathrm{dBm}$ for the hybrid system. It is observed that the BER is increased at storm rain and heavy natural haze by means of reducing the power transfer.

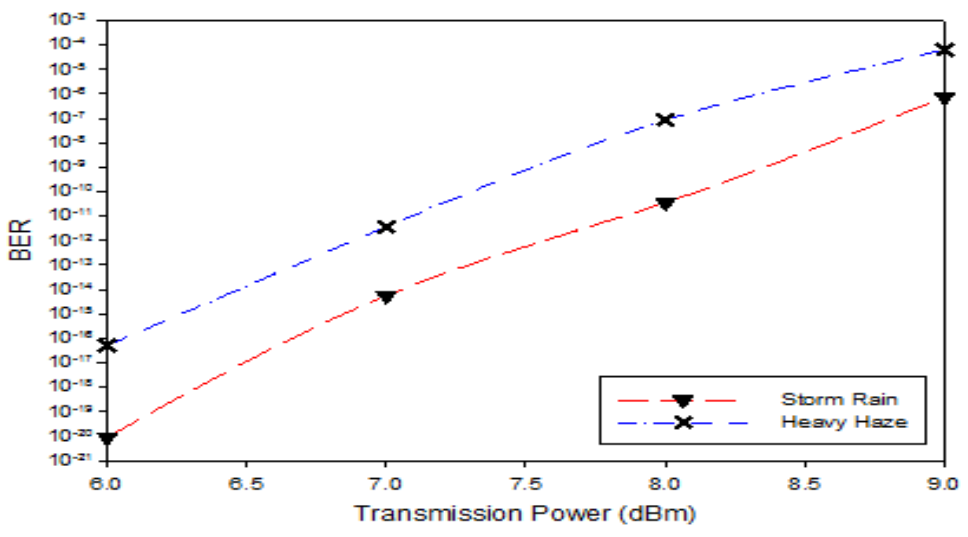

Figure 6. The BER versus power transfer

The variations of the transmission power have effect on the power receiver. Figure 7 shows the power transmission is compared with the power receiver and the range of power transfer from 1 to $6 \mathrm{dBm}$. It is observed that the received outdoor power is increased by increasing the transmitted power or power transfer. Figure 7 displays the reducing of reception relating to transmission power through a storm rain and heavy haze. 


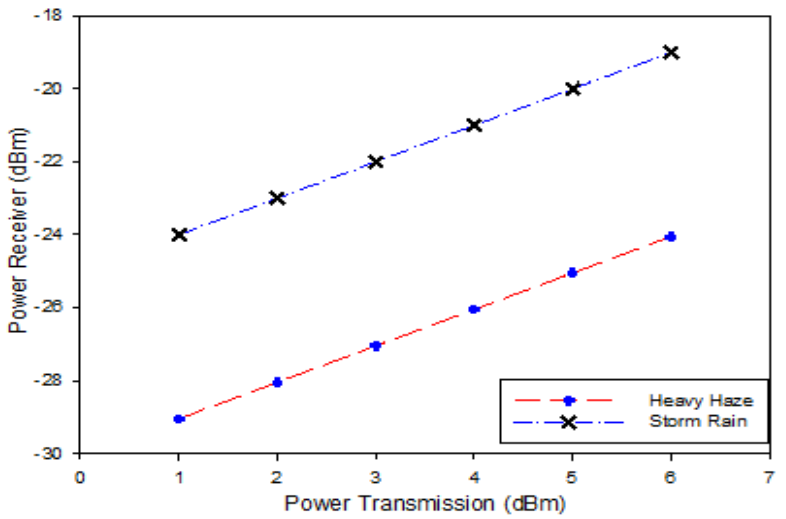

Figure 7. The effect of transmission power on the reception power

The simulated results of reducing noise are examined by eye diagrams at applying the proposed "hybrid SCM-SAC-OCDMA" optical network that is connecting with FSO technique are illustrated in figure 8 at two different ranges. Figure 8 shows that the attenuation, number of users, and input power were set to be $500 \mathrm{~m}, 5$ users, and $6 \mathrm{dBm}$ respectively. It is shown that the eye in eye diagram is extended and cleared at increasing of BER at the natural storm rain. This phenomenon is illustrated in Figure 9 when the number of users, input power, and attenuation were set to be 5 users, $6 \mathrm{dBm}, 2500 \mathrm{~m}$ respectively. Also from figure 8(b), the BER clearly increases at the heavy natural haze. The simulation was running with storm rain because of rain attenuation is much higher than haze, so the results of eye diagram with storm rain give an improvement for system performance. Therefore, a special optimization is needed to achieve a better system performancethat involved link range number of user'soptimization. In this part of the research, we show how the attenuation has a significant impact on system performance (BER) and link range (km). So that, rain is the biggest affecting in the free space optical systems. However, it still can be successfully with considered to the parameters of the rain attenuation.

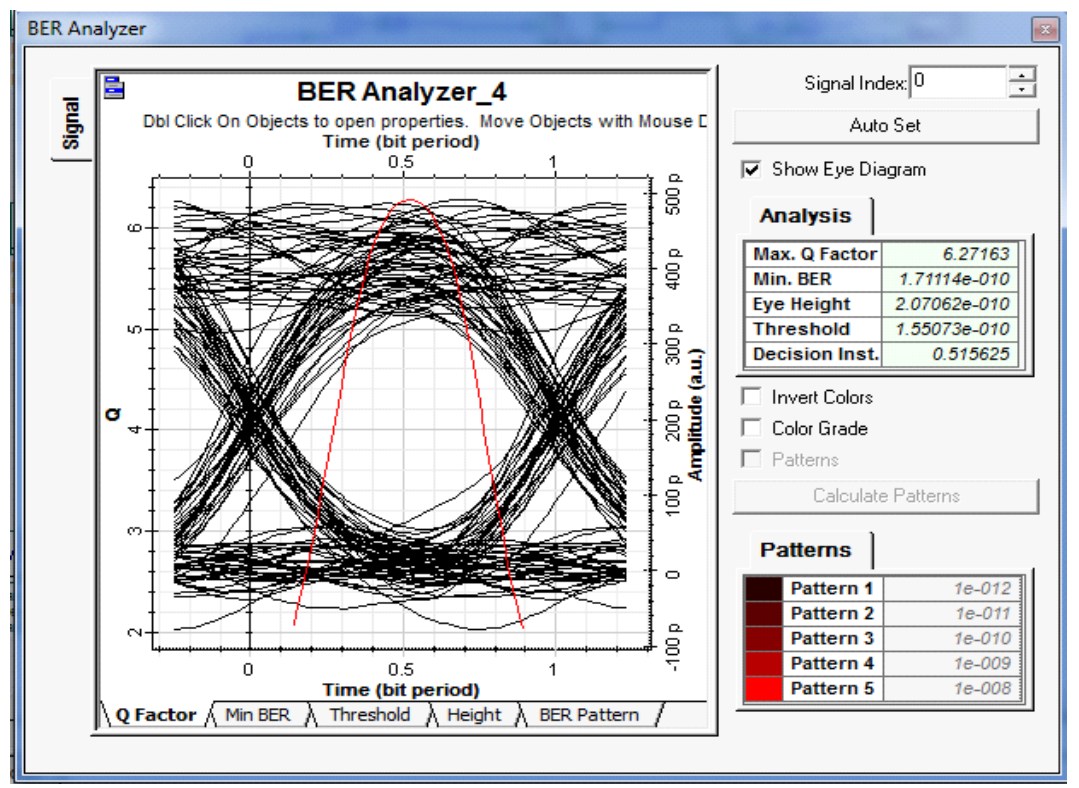

(a) 


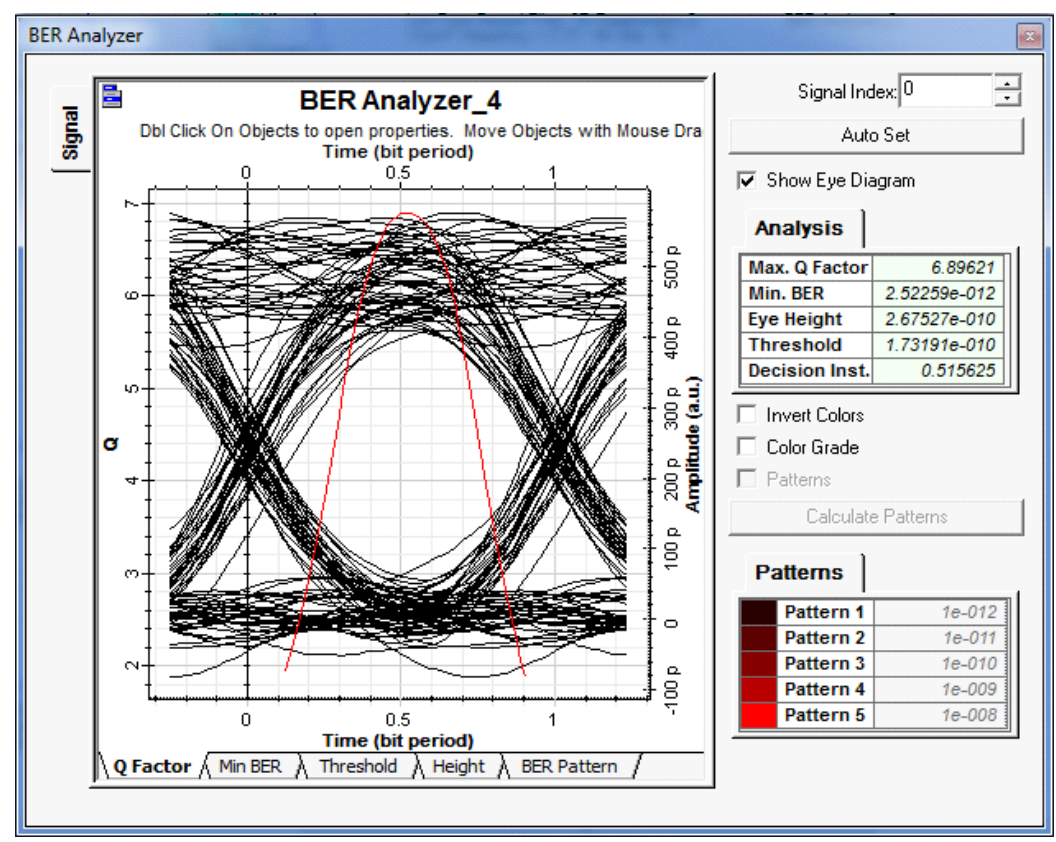

(b)

Figure 8 . The taken eye diagram at channel 1, (a) with distance of $500 \mathrm{~m}$ at storm rain, (b) at range of $2500 \mathrm{~m}$ with heavy haze

\section{THE PROPOSED SYSTEM APPLICATION}

The radio over fiber is indirectly modulated the optical signal using Mach-Zehnder modulator from a continuous wave laser diode of wavelength in nanometers. At the receiving end of optical fiber link, optical signals are weak and carrying information that need to be converted to strong electrical signal to estimate the originally transmitted signals. Therefore, there are three functions, have to be done in the optical receiver such as, estimation of transmitted message, amplification, and optical signal conversion to electrical signal. By these three functions, the optical receiver is similar to the radio receiver accept no amplification in optical system. To see the improved performance on UWB optical receiver, we need to apply the proposed optical system to reduce the probability of error bits.

This application is to show the effects of using fiber in wireless channel through inside buildings (indoor propagation) using ultra-wideband (UWB) technology. By using RoF technology, data capacity of optical networks is combining with mobility and flexibility of wireless networks without increment in significant cost [16], [17]. Also by RoF, information can be transported over optical fiber with modulating in direct or indirect light with radio signal. There is an external modulator to modulate the optical signal called Mach Zehnder modulator (MZM) and Mach Zehnder Interferometer (MZI) is used to split this signal into 2 paths [18], [19], and [20]. After summing the 2 signals, they interfere depending on delay time with each other. MZM is applying to convert the electrical to optical signals and send them to multiplexer to combine the signals in optical domain. These signals are passed to demultiplexer to split the signal into two ways, one is passed into the fiber to convert optical signal to electrical signal and then to spectrum analyzer to be detected by optical detector.

The other way is passed directly to spectrum analyzed to show the symbol error rate (SER) in time domain or to detect the electrical signal. The spectrum analyzer detections are illustrated in Figure 10 to represent the simulation results of the SER versus number of active users for UWB signals in optical detector and non-optical detector. The SER characteristic without optical link is bad because the received signal travels through the wireless indoor channel that is affected by fading, path losses, and shadowing before entering the RoF link. Although there is some interference between the wireless and optical wired channels, the power penalties are small and can be further reduced by using optical filter. By using MATLAB software, the simulation results are shown in Figurer 9. From simulation results the optical receiver is better than electrical receiver when using MZM so that, the performance of UWB over fiber system is examined. As the SER, U, and SNR are the significant parameters for system performance indication, they are defined as expressed bellow: 


$$
\begin{aligned}
& h(t)=R x(t) \otimes h(t)+n(t) \\
& S N R=\left(\frac{R\left(P_{s 1}-P S O\right.}{\sigma_{0}+\sigma_{1}}\right) \\
& S E R=\frac{U}{2} \operatorname{erfc}\left(\sqrt{\frac{S N R}{2}}\right)
\end{aligned}
$$

where $\mathrm{x}(\mathrm{t})$ is the transmitted signal, $\mathrm{h}(\mathrm{t})$ is the channel impulse response, $\otimes$ denotes convolution, $\mathrm{n}(\mathrm{t})$ is the Gaussian noise, erfc is the error function, $\mathrm{P}_{\mathrm{s} 1}$ is signal power of bit $1, \mathrm{P}_{\mathrm{s} 0}$ is signal power ofbit $0, \sigma_{0}$ and $\sigma_{1}$ are the noise variances associated with the transmitted signal 0 and 1respectively, and $\mathrm{R}$ is the photodetector responsivity.

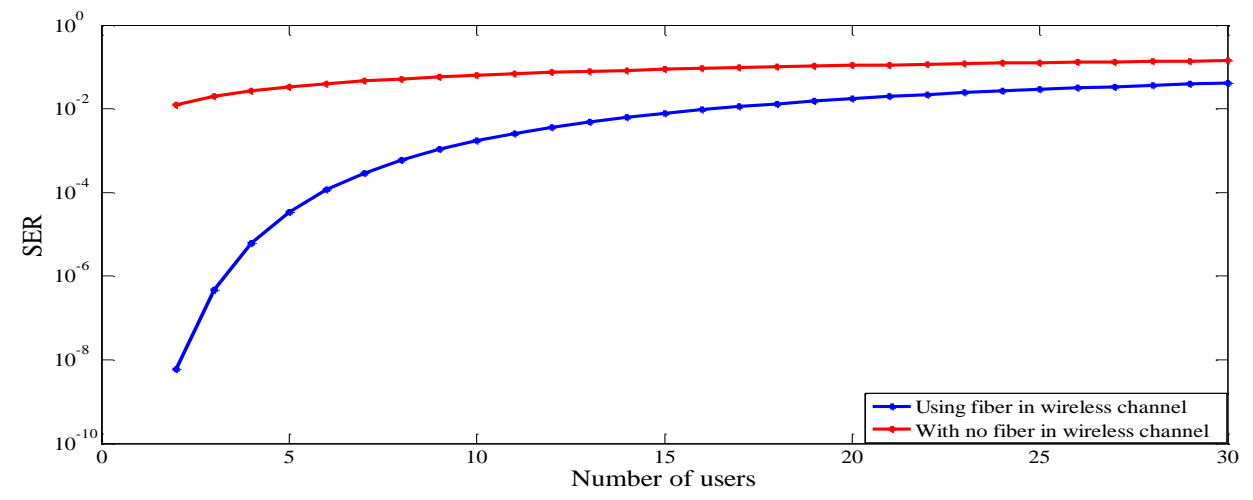

Figure 9. BER vs. number of users for UWB signals

\section{CONCLUSIONS}

The working proposed mesh network system is now promising technique in optical transmission to improve the trusting of high data rate indoor or outdoor reception and transmission at long or short ranges of wireless systems at optical communication links. So that, proposed research is quit can be used in wireless systems with high data rate velocity in propagation by communication links reception or transmission. Furthermore, the basic idea of the research is to cross or overcome the natural bad environments that are happened by heavy haze and storm rain over optical FSO technique for reception or transmission. So that, the requirement of this work is to minimize or reduce the normally effect on BER at high capacity of data rate propagation through optical technique used FSO. Results that are gotten by simulation process for 5 users are showing with decreasing of BER. This decreasing and increasing of received power depending on maximizing or amplifying the power transmission at varying or unexpected conditions such as haze and heavy rain. The simulation results are supporting the "hybrid SCM-SAC-OCDMA" optical instruments enhancement in free space for long ranges or distances, which reduce the required stations number of reception and transmission. Also in this paper, we can conclude that the effect of RoS link on UWB signals by simulation results for BER at different number of users. From this study, we enhanced that the proposed optical system is more suitable in services for UWB indoor systems by reducing the probability of bit error at the receiving end of the system.

\section{ACKNOWLEDGEMENTS}

I have done this work in my department laboratories of Electrical Engineering College. So my regards and thanks to the staff of these laboratories. Also I would like to thank the dean of this college for his support to finish the simulation work. 


\section{REFERENCES}

[1] C.C. Yang, "Code space enlargement for hybrid fiber radio and baseband OCDMA PONs", Journal of Light wave Technology, vol. 29, pp. 1394-1400, 2011.

[2] T.H. Abd, S.A. Aljunid, H.A. Fadhil, I.F. Radhi, Ahmad R.B. and M.A. Rashid,"Performance improvement of hybrid SCM SAC-OCDMA networks using multi-diagonal code", University Malaysia Perlis,School of Computer and Communication Engineering, vol. 7(11), pp. 1262-1272, 2012.

[3] V.G.A. Carneiro, G.K. Rodrigues, M. Thereza, and M.R. Giraldi, "Performance analysis of a 2D double hardlimited OCDMA system over FSO link under strong turbulence for defense applications", 2012.

[4] B. Patnaik and P.K. Sahu, "Novel QPSK modulation for DWDM free space optical communication system", pp. 170-175, 2012.

[5] B. Ciftcioglu, J. Gao, R. Berman, M. Jain, D. Moore, G. Wicks, M. Huang, E.G. Friedman, and Hui Wu, "Recent progress on 3-D integrated intra-chip free-space optical interconnect", 2012, pp. 56-57.

[6] Mohammad Ali Shah, Shafie Abd Latiff, \& Riaz T., "Performance Measurement of Free-Space Optical $980 \mathrm{~nm}$ Channel Using Multiple Sets of Environmental Conditions", Wireless Personal Communication, vol 85, Issue 2, pp. 345-357, 2015.

[7] W.R.H. Wan Ruslan, S.M. Idrus, A. Ramli, N. Ramli, A.S. Mohd Supa'at, and F. Mohd Nor, "Terrestrial FREE Space Optic Propagation Analysis Considering Malaysia Weather Condition", Journal Teknologi (Sciences and Engineering),vol. 54, pp. 217-229, 2011.

[8] S. Hashmi and H.T. Mouftah, "Integrated optical/wireless networking", 2004, pp. 2095-2098.

[9] A. Malik and P. Singh, "Free Space Optics: Current Applications and Future Challenges", International Journal of Optics, Hindawi Publishing Corporation, pp. 1-7, 2015.

[10] T.H. Abd, S.A. Aljunid, H.A. Fadhil, R.A. Ahmad, and N.M. Saad, "Modeling and simulation of multi diagonal code with zero cross correlation for SAC-OCDMA networks", 2011.

[11] M. Noshad and M. Brandt-Pearce, "Expurgated PPM using symmetric balanced incomplete block designs", IEEE Communications Letters, vol. 16, pp. 968-971, 2012.

[12] F.H. Mustafa, A.S. Mohd Supa'at, and F.D. Mahad, "Simulation of FSO Transmission at Petaling Jaya due to Attenuations Effect", ELEKTRIKA, vol. 12, no. 1, pp. 30-34, 2010.

[13] M. Zuliyana, M.S. Anuar, S.A. Aljunid, A.K. Rahman, C.B.M. Rashidi, and M.S.A. Bakar, "Performance Analysis of FSO with Haze Attenuation Consequence Acclimatize in Tropical Rainforest Environment", ARPN Journal of Engineering and Applied Sciences, vol. 10, no. 3, pp. 1332-1337, February 2015.

[14] M. Motealleh and M. Maesoumi, "Simulation of a SAC-OCDMA 10 User ×15 Gb/s System Using MD Code", International Journal of Optics and Applications, vol. (4), no. 1, pp. 20-26, 2014.

[15] T.H. Abd, S.A. Aljunid, Hilal A. Fadhil, Ibrahim Fadhil Radhi, Ahmad R.B., and M.A. Rashid, "Performance Improvement of Hybrid SCM-SAC-OCDMA Network Using Multi-Diagonal Code", Scientific Research and Essays, vol. 7 (11), pp. 1262-1272, March 2012.

[16] H.A. Fadhil, A. Amphhawanb, H.M.R. Al-Khafajia, and N. Ahmeda, "Optimization of free space optics parameters: An optimum solution for bad weather conditions", Optik - Int. J. Light Electron Opt. 2013.

[17] M. Aminikashani and M. Kavehrad, "Error Performance Analysis of FSO Links with Equal Gain Diversity Receivers over Double Generalized Gamma Fading Channels", Cornell University Library, May 2015

[18] S. Pan, and J. Yao, "UWB-Over-Fiber Communications: Modulation and Transmission", Journal of Lightwave Technology, vol. 28, no. 16, pp. 2445-2455, August 2010.

[19] J.P. Soler and R.L. Sáez, "Hybrid UWB and WiMAX radio-over-multi-mode fibre for in-building optical networks", Journal of Optics, vol. 16(1), pp. 1-8, 2014.

[20] Y. Li and A.M. Weiner, "Photonic-Assisted Error-Free Wireless Communication with Multipath Precompensation Covering 2-18 GHz", Journal of Lightwave Technology, vol. 34, NO. 17, pp. 4153-4160, September 2016. 


\section{BIOGRAPHIES OF AUTHORS}

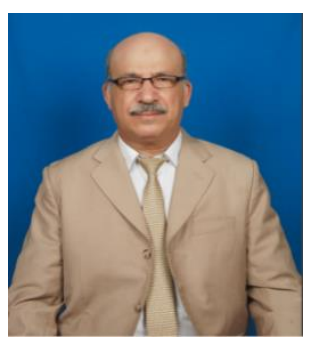

Ass. Prof. Dr. Rashid Ali Fayadh received his B.Sc. degree from Middlesex University / Engineering College / UK, in 1986 and worked as an electronic warfare engineer in Iraqi air force up to 1998. He received the M.Sc. degree from University of Technology/ Al-Rasheed College / Baghdad-Iraq in 2000 and received the Ph.D degree from University Malaysia Perlis, Malaysia, Perlis. He is a lecturer starting from 2001 upto now in the College of Electrical Engineering Techniques, Middle Technical University, Baghdad, Iraq. He is head of electrical power engineering department. $\mathrm{He}$ is doing in fields of wireless communication systems, wireless sensors, signal processing, advanced electronics, wireless antenna designs, and the specific focus on ultra-wideband (UWB) technologies. He is IEEE member and has published more than 50 reviewed journal and conference papers.

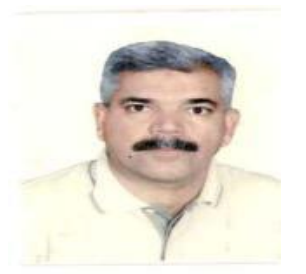

Ass. Prof. Dr. Mousa Kadhim Wali received the B.Sc. degree in Electrical Engineering from Baghdad University, Iraq in 1984. The M.Sc. degree in Communication \& Electronic Engineering from Bradford University, U.K. in 1991, the $\mathrm{PhD}$ degree in computer engineering from University Malaysia Perlis (UniMAP). He is currently Dean of Electrical Engineering Technical College, Baghdad, as Assistant Professor. His current fields of interest are in Hypovigilance detection, Antenna and wireless communication \& Networks, and DSP.

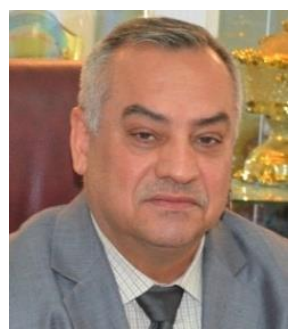

Ass. Prof. Dr. Mehdi F. Bonneya born in Iraq in 1958. He received the B.SC degree at 1979, the M.Sc. degree at 1986, and Ph.D. degree from the University of Technology - Baghdad-Iraq. He is dean of Kut Technical Institue. His current research interests include power system stability, wind turbine plant, and magnetic field analysis in electrical machines. 